\title{
Factors influencing the development of early- or late-onset Parkinson's disease in a cohort of South African patients
}

\author{
C van der Merwe, W Haylett, J Harvey, D Lombard, S Bardien, J Carr
}

Background. Neurodegenerative disorders such as Parkinson's disease $(\mathrm{PD})$ contribute significantly to global disease burden. PD can be categorised into early-onset PD (EOPD) with an age at onset (AAO) of $\leq 50$ years and late-onset PD (LOPD) with an AAO of $>50$ years.

Aims. To identify factors influencing EOPD and LOPD development in a group of patients in South Africa (SA).

Methods. A total of 397 unrelated PD patients were recruited from the Movement Disorders Clinic at Tygerberg Hospital and via the Parkinson's Association of SA. Patient demographic and environmental data were recorded and associations with $\mathrm{PD}$ onset (EOPD v. LOPD) were analysed with a Pearson's Chi-squared test. The English- and Afrikaans-speaking (Afrikaner) white patients were analysed separately.
Results. Logistic regression analysis showed that ethnicity $(p<0.001)$ and family history $(p=0.004)$ were independently associated with AAO of PD. Average AAO was younger in black, coloured and Afrikaner patients than English-speaking white patients. A positive family history of PD, seen in $31.1 \%$ of LOPD patients, was associated with a younger $\mathrm{AAO}$ in the study population.

Conclusions. These associations may be attributed to specific genetic and/or environmental risk factors that increase PD susceptibility and influence the clinical course of the disorder. More studies on PD in the unique SA populations are required to provide novel insights into mechanisms underlying this debilitating condition.

S Afr Med J 2012;102(11):848-851. DOI:10.7196/SAMJ.5879
Parkinson's disease (PD) is a debilitating neurodegenerative disorder with no known cure. PD is prevalent in approximately $1 \%$ of individuals aged $>65$ years, increasing to $4 \%$ in individuals aged $>80$ years. ${ }^{1}$ In a study of the most populous countries in Western Europe and the world (including Germany, France, Nigeria and Japan), the number of PD-affected individuals in 2005 was estimated to be $4.1-4.6$ million. This figure is expected to double by $2030 .{ }^{2} \mathrm{PD}$ epidemiological data are not available for South Africa (SA).

PD aetiology is not fully understood, but is thought to involve an interaction between genetic and environmental risk factors. ${ }^{3}$ Important insights into genetic causes have been made, largely due to the discovery of causative mutations in several genes. ${ }^{4}$

$\mathrm{PD}$ cases can be subcategorised based on age at onset (AAO): early-onset PD (EOPD) with an AAO $\leq 50$ years, and late-onset PD (LOPD) with an AAO $>50$ years. ${ }^{5}$ EOPD and LOPD differ in clinical presentation and underlying genetic aetiology. EOPD exhibits a slower disease progression, a good response to levodopa therapy and additional signs such as dystonia and prominent levodopa-induced

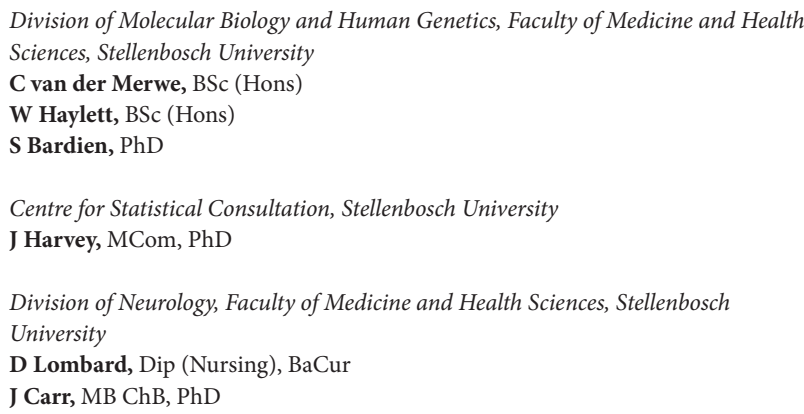

Corresponding authors: J Carr (jcarr@sun.ac.za) and S Bardien (sbardien@sun.ac.za)

Joint first authors: $C$ van der Merwe and W Haylett dyskinesias. ${ }^{6}$ Mutations in causative genes that are inherited in an autosomal recessive manner (e.g. parkin and PINK1) are associated with familial EOPD, whereas autosomal dominant mutations (in SNCA and LRRK2) typically contribute to familial LOPD. ${ }^{4}$

Although old age is a significant risk factor for PD, additional factors include a positive family history and environmental elements such as drinking well-water, living in a rural area, farming and pesticide exposure. ${ }^{7}$ Exposure to the insecticide rotenone, ${ }^{8}$ the herbicide paraquat ${ }^{9}$ and the neurotoxin 1-methyl-4-phenyl-1,2,3,6tetrahydropyridine (MPTP) ${ }^{10}$ have been shown experimentally to cause mitochondrial dysfunction and subsequent parkinsonism in laboratory animals. Studies investigating PD associations with chemical products, such as metals, solvents, paints and other chemicals, have shown conflicting findings. ${ }^{11}$ Notably, cigarette smoking and coffee consumption are thought to protect against PD development. ${ }^{12,13}$

We aimed to identify factors influencing EOPD and LOPD development in a group of $397 \mathrm{PD}$ patients in SA.

\section{Methods}

The study was approved by the Committee for Human Research at the University of Stellenbosch (2002/C059). A total of 397 unrelated PD patients were recruited, with written informed consent, from the Movement Disorders Clinic at Tygerberg Hospital, a tertiary referral hospital in Cape Town, and through the Parkinson's Association of SA. PD diagnosis was made by a movement disorder specialist according to the UK Parkinson's Disease Society Brain Bank Research criteria. Participants were recruited as part of ongoing genetics research investigating the underlying genetic basis of PD in different ethnic groups in SA.

Recruited ethnic group $\mathrm{s}^{14}$ included white $(288 ; 72.5 \%)$, coloured (86; 21.7\%), black (18; 4.5\%) and Indian/Asian (5; 1.3\%). Ethnicity was self-reported. White Afrikaner patients were analysed separately to the 'non-Afrikaner' white patients. The Afrikaner population originated in SA and descended from a group of 2000 mainly male progenitors who arrived in the Cape in the $17^{\text {th }}$ and $18^{\text {th }}$ centuries; ${ }^{15}$ they were predominantly of Dutch, German and French origin. Initially, due to cultural, religious and language 
differences, the Afrikaner population remained largely isolated. Indicative of their unique ancestral lineage, several rare inherited disorders such as porphyria variegata and Gaucher's disease occur at unusually high frequencies in this population, possibly due to genetic founder effects. ${ }^{16}$ The coloured ethnic group is an admixture of indigenous African, European, South Asian and Indonesian populations. ${ }^{17}$

Sampled clinical data included AAO and family history of PD; the latter defined as having $\geq 1$ family member (first-, second- or third-degree relative) with possible PD. Environmental data for each index patient, collected with a questionnaire, were recorded as part of a collaboration with the international Genetic Epidemiology of Parkinson's Disease (GEO-PD) Consortium. Information was obtained on current and previous occupation, smoker status, coffee consumption and pesticide exposure prior to PD diagnosis. Optional responses were 'ever' or 'never'; 'ever' was defined as having smoked $\geq 1$ cigarette per day, consumed $\geq 1$ cup of coffee per day, and broadly, as the use of a herbicide, fungicide or insecticide, prior to PD onset.

Data were analysed descriptively, using means and standard deviations for continuous data and frequencies counts and percentages for categorical data. Associations between AAO (binary classification: $\leq 50$ years of age v. $>50$ years of age) and demographic and environmental variables were analysed with a Pearson's Chi- squared test. In cases of small cell frequencies, a Fisher's Exact test was used to assess association. A multiple logistic regression was used to test the association between demographic variables and $\mathrm{AAO}$ after adjusting for the presence of other predictor variables. Where the actual (continuous) AAO was analysed, a Student's $t$-test was used. A significance level of $5 \%$ was applied throughout.

\section{Results}

A total of 397 patients were recruited over a 5-year period (2007 2011) (Table 1); $62.5 \%$ (248) were male and $34.8 \%$ (138) had a family history of PD. For the first 3.5 years, the study focussed mainly on recruiting EOPD patients and/or those with a positive family history of $\mathrm{PD}$ (as these were thought to harbour a greater genetic component). Subsequent to the identification of mutations associated with LOPD, criteria also included LOPD and sporadic (non-familial) cases.

A significant association was found between $\mathrm{AAO}$ and ethnicity; the black, coloured and white Afrikaner patients had a younger mean AAO than the 'non-Afrikaner' whites ( $p=0.00038$ ) (Table 1 and Fig. 1). The black patients exhibited the youngest $\mathrm{AAO}$ but were limited in numbers $(n=18)$; this finding requires verification. A positive family history was associated with a younger $\mathrm{AAO}(p=0.01445)$. No association was found between $\mathrm{AAO}$ and gender or an environmental factor (cigarette smoking, coffee drinking, pesticide use and chemical exposure) (Table

Table 1. Patient demographic and clinical characteristics $(N=397)$

\begin{tabular}{|c|c|c|c|}
\hline & $\begin{array}{l}\text { EOPD } \\
n(\%) \\
\end{array}$ & $\begin{array}{l}\text { LOPD } \\
n(\%)\end{array}$ & $p$-value \\
\hline Gender $(N=397)$ & & & 0.70145 \\
\hline Male $(n=248)$ & $71(64.0)$ & $177(61.9)$ & \\
\hline Female $(n=149)$ & $40(36.0)$ & $109(38.1)$ & \\
\hline Ethnic group $(N=397)$ & & & 0.00038 \\
\hline White ('non-Afrikaner') $(n=167)$ & $27(24.3)$ & $140(49.0)$ & \\
\hline White (Afrikaner) $(n=121)$ & $44(39.7)$ & $77(26.9)$ & \\
\hline Coloured $(n=86)$ & $30(27.0)$ & $56(19.6)$ & \\
\hline Black $(n=18)$ & $8(7.2)$ & $10(3.5)$ & \\
\hline Indian $(n=5)$ & $2(1.8)$ & $3(1.0)$ & \\
\hline Family history of PD ( $N=397)$ & & & 0.01445 \\
\hline Yes $(n=138)$ & 49 (44.1) & $89(31.1)$ & \\
\hline No $(n=259)$ & $62(55.9)$ & $197(68.9)$ & \\
\hline \multicolumn{4}{|l|}{ Environmental factors ${ }^{\star}$} \\
\hline Cigarette smoking $(N=283)$ & & & 0.28642 \\
\hline Ever $(n=107)$ & $17(31.5)$ & $90(39.3)$ & \\
\hline Never $(n=176)$ & $37(68.5)$ & $139(60.7)$ & \\
\hline Coffee drinking $(N=283)$ & & & 0.40860 \\
\hline $\operatorname{Ever}(n=213)$ & $43(79.6)$ & $170(74.2)$ & \\
\hline Never $(n=70)$ & $11(20.4)$ & $59(25.8)$ & \\
\hline Pesticide use $(N=278)$ & & & 0.85839 \\
\hline Ever $(n=88)$ & $17(32.7)$ & $71(31.4)$ & \\
\hline Never $(n=190)$ & $35(67.3)$ & $155(68.6)$ & \\
\hline Chemical exposure $(N=280)$ & & & 0.27767 \\
\hline Yes $(n=160)$ & $35(63.6)$ & $125(55.6)$ & \\
\hline No $(n=120)$ & $20(36.4)$ & $100(44.4)$ & \\
\hline
\end{tabular}




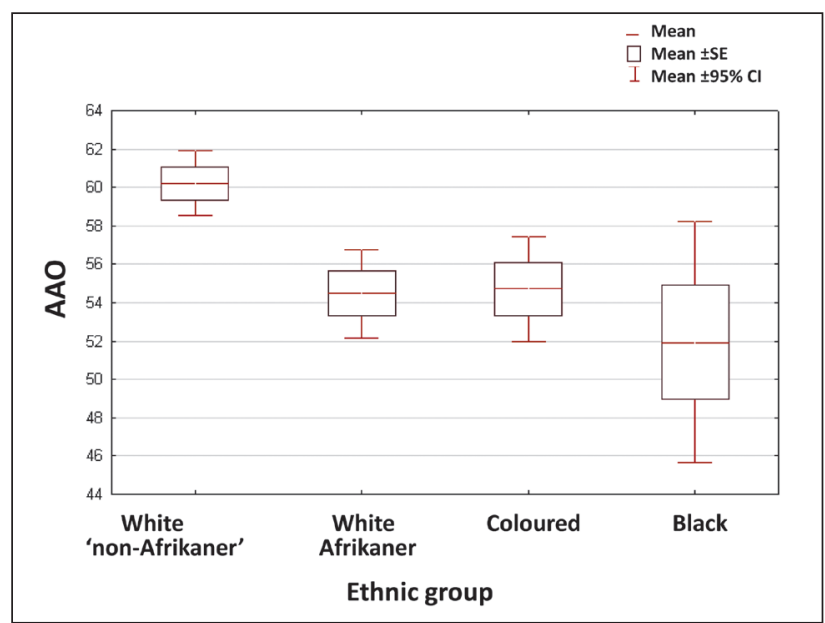

Fig. 1. Box and whisker plots of patient AAO of PD v. ethnicity. Data are represented as means.

1). This may be attributed to small sample sizes; relevant data were not available for every participant. Logistic regression analysis showed that ethnicity and family history were independently associated with AAO ( $p<0.001$ and $p=0.004$, respectively). Mean AAO was 56.8 years (SD \pm 12.4 ; 95\% CI 55.6 - 58.0, range 17 - 87) (Fig. 2), emphasising that PD also occurs in comparatively young individuals.

A positive family history was found in $31.1 \%$ of LOPD patients (Table 1). This may be an underestimate: one LOPD patient (individual III-1; Fig 3) initially reported no family history. However, we previously identified a disease-causing mutation (R1441C in the LRRK2 gene) in the patient (unpublished data), which led to a subsequent family follow-up. A sibling of the patient (individual III5) was shown to harbour the mutation and later clinically diagnosed with PD; the sibling reported 2 other possibly affected individuals who were deceased (individuals II-1 and II-2).

\section{Discussion}

This study raises awareness about the relatively high frequency of PD cases with young onset and a positive family history among SA patients. This retrospective investigation demonstrated that the black, white Afrikaner and coloured patients had a younger AAO than 'non-Afrikaner' white patients. A positive family history was also associated with a younger AAO. These associations may be attributed to specific genetic and/or environmental risk factors that increase PD susceptibility and influence the clinical course of the disorder.

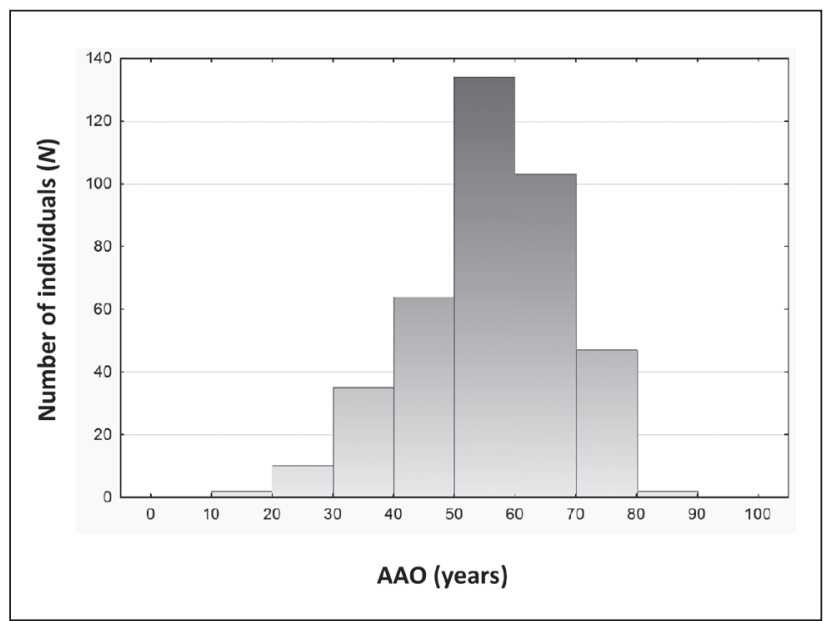

Fig. 2. Distribution of AAO of PD among patients ( $\mathrm{N}=397)$.

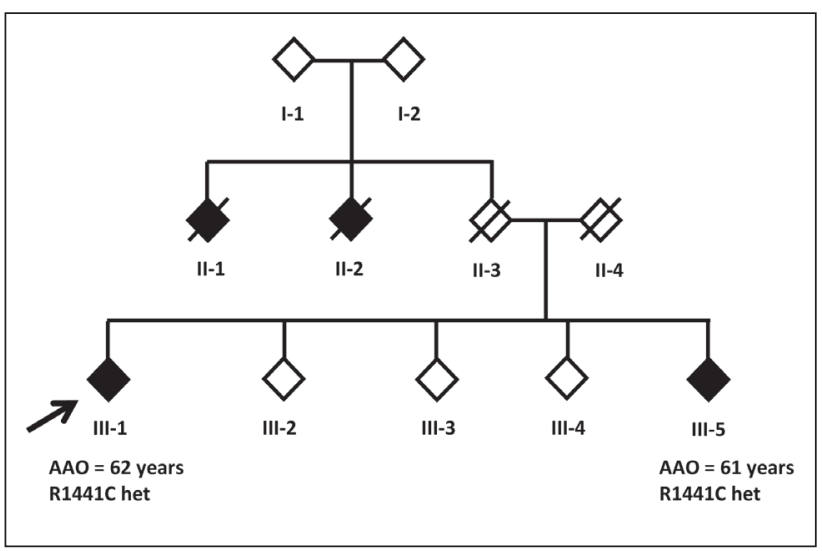

Fig. 3. Pedigree of a SA family with PD. The individuals are depicted as diamond symbols; filled-in symbols indicate PD-affected individuals. The arrow designates the index case. A line through the diamond symbol denotes a deceased individual. $R 1441 \mathrm{C}$ het = individual heterozygous for the R1441C mutation in the LRRK2 gene.

Approximately one-third of LOPD patients exhibited positive family histories, challenging the assumption that LOPD manifests sporadically, and demonstrating a possible genetic contribution. We contend that positive family histories are often underreported and, consequently, underestimated. The initial analysis of family history of PD may be misleading unless further intensive follow-up and genetic work-up of the families is performed.

In this study, gender had no effect on AAO, in accordance with the literature. ${ }^{18}$ However, $62.5 \%$ of patients were male, possibly due to recruitment bias. Some studies have shown that men are 1.5 times more likely to develop PD than females. ${ }^{19}$ However, this trend is not consistent across studies.

We found no significant association between cigarette smoking, coffee drinking, pesticides or hazardous chemicals exposure with AAO of PD, despite work by others showing the contribution of these factors to PD susceptibility. ${ }^{13,20}$ Exposure to environmental risk factors may increase PD susceptibility without necessarily affecting AAO. A lack of exposure data for unaffected control individuals precluded any tests for such an association.

Study limitations include the relatively small samples sizes (particularly for the black group) and a lack of environmental variable data for every participant. Furthermore, recruitment bias may have been introduced, although it is unclear what influence this may have had on participant AAO. Study patients were part of an ongoing research project investigating $\mathrm{PD}$ genetic aetiology; they were recruited from a tertiary academic centre and various PD support groups of the Parkinson's Association of SA. Coloured patients were recruited primarily from Tygerberg Hospital, 'non-Afrikaner' white patients were recruited predominantly from support groups, and white Afrikaners were recruited almost equally from both sources.

\section{Conclusion}

There is little knowledge on the environmental and genetic factors associated with PD in SA. Although our findings are preliminary, studies on unique and diverse SA populations are needed to provide novel insights into the risk factors and pathogenesis underlying this debilitating disorder.

Acknowledgements. We gratefully acknowledge participant involvement and the following funders: Medical Research Council of SA, the Harry and Doris Crossley Foundation, and the University of Stellenbosch. 
References

1. De Lau LM, Breteler MM. Epidemiology of Parkinson's disease. Lancet Neurol 2006;5(6):525-535. [http://dx.doi.org/10.1016/S1474-4422(06)70471-9]

Dorsey ER, Constantinescu R, Thompson JP et al. Projected number of people with Parkinson disease in the most populous nations, 2005 through 2030. Neurology 2007;68(5):384-386. [http://dx.dol. org/10.1212/01.wnl.0000247740.47667.03]

3. Sherer TB, Betarbet R, Greenamyre JT. Environment, mitochondria and Parkinson's disease Neuroscientist 2002;8(3):192-197. [http://dx.doi.org/10.1177/1073858402008003004]

Gasser T. Mendelian forms of Parkinson’s disease. Biochim Biophys Acta 2009;1792(7):587-596. [http://dx.doi.org/10.1016/j.bbadis.2008.12.007]

5. Marder KS, Tang MX, Mejia-Santana H, et al. Predictors of parkin mutations in early- onset Parkinson' disease: the consortium on risk for early-onset Parkinson's disease study. Arch Neurol 2010 67(6):731738. [http://dx.doi.org/10.1001/archneurol.2010.194]

6. Schrag A, Schott JM. Epidemiological, clinical and genetic characteristics of early-onset parkinsonism. Lancet Neurol 2006;5(4):355-363. [http://dx.doi.org/10.1016/S1474-4422(06)70411-2]

Priyadarshi A, Khuder SA, Schaub EA, Privadarshi SS. Environmental risk factors and Parkinson disease: A metaanalysis. Environ Res 2001;86(2):122-127. [http://dx.doi.org/10.1006/enrs.2001.4264] 8. Betarbet R, Sherer TB, Mackenzie G, Garcia-Osuna M, Panov AV, Greenamyre JT Chronic systemic pesticide exposure reproduces features of Parkinson's disease. Nat Neurosci 2000;3(12):1301-1306. http://dx.doi.org/10.1038/81834]

9. McCormack AL Thiruchelvam M, Manning-Bog AB, et al. Environmental risk factors and Parkinson's disease: Selective degeneration of nigral dopaminergic neurons caused by the herbicide paraquet.

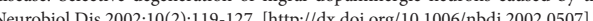
Pre

. Przedborski S, Tieu K, Perier C, Vila M. MPTP as a mitochondrial neurotoxic model of Parkinson's disease. J Bioenerg Biomembr 2004;36(4):375-379. [http://dx.doi.org/10.1023/B:JOBB.0000041771.66775.d5] NeurolSci 2004;217(2):169-174. [http://dx.doi.org/10.1016/j.jns.2003.09.014]
2. Morens DM, Grandinetti A, Reed D, White LR, Ross GW. Cigarette smoking and protection from (1995:45(6):1041-1051.

13. Hernan MA, Takkouche B, Caamano-Isorna F, Gestal-Otero JJ. A meta-analysis of coffee drinking cigarette smoking, and the risk of Parkinson's disease. Ann Neurol 2002;52(3):276-284. [http://dx.do. org/10.1002/ana.10277]

14. Statistics South Africa. Mid-year Population Estimates 2011. Pretoria: SSA, 2011. http://www.statssa gov.za/publications/P0302/P03022011.pdf (accessed 19 March 2012)

5. Heese JA. Die herkoms van die Afrikaner 1657 - 1867. Cape Town: AA Balkema, 1971.

16. Botha MC, Beighton P. Inherited disorders in the Afrikaner population of southern Africa. Part Historical and demographic background, cardiovascular, neurological, metabolic and intestin conditions. S Afr Med J 1983;64(16):609-61

17. Patterson N, Peterson DC, van der Ross RE, et al. Genetic structure of a unique admixed population implications for medical research. Hum Mol Genet 2010;19(3):411-419. [http://dx.doi.org/10.1093 hmg/ddp505]

18. Van Den Eeden SK, Tanner CM, Bernstein AL, et al. Incidence of Parkinson's disease: variation by age, gender and race/ethnicity. Am J Epidemiol 2003;157(11):1015-1022. [http://dx.doi.org/10.1093 aje/kwg068]

9. Twelves D, Perkins KS, Counsell C. Systematic review of incidence studies of Parkinson's disease. Mo Disord. 2003;18(1):19-31. [http://dx.doi.org/10.1002/mds.10305]

20. Firestone JA, Smith-Weller T, Franklin G, et al. Pesticides and risk of Parkinson disease: population-based case-control study. Arch Neurol 2005;62(1):91-95. [http://dx.doi.org/10.1001 archneur.62.1.91]

Accepted 7 May 2012

\title{
Risk factors for substance use in pregnant women in South Africa
}

\author{
B Vythilingum, A Roos, S C Faure, L Geerts, D J Stein
}

Objectives. To study the prevalence of alcohol and substance use in a South African antenatal population and its correlates with sociodemographic factors, depression and perceived stress.

Methods. A prospective self-report study on all women presenting for their first antenatal visit who consented to the study at a midwife obstetric unit (MOU) in the East Metropole district, Cape Town, using the Alcohol Use Disorders Identification Test (AUDIT), Drug Use Disorders Identification Test (DUDIT), Edinburgh Depression Scale (EDS) and Perceived Stress Scale (PSS). Statistical analyses using the chi-square test, separate one-way analyses of variance (ANOVA) and logistic regression analyses were performed as appropriate. Outcome measures were depression, alcohol use and substance use.

Results. The questionnaire was completed by 323 women. During pregnancy $36.8 \%$ of women smoked, $20.2 \%$ used alcohol and $4 \%$ used substances. Using EDS cut-off scores of 12 and 15 respectively, $48.9 \%$ and $33.6 \%$ of the sample had scores consisten with major depression. An EDS cut-off score of 12 was significantly associated with both alcohol use $(25.9 \%$ v. $15.2 \%, p=0.019)$ and risky drinking $(76.9 \%$ v. $36.8 \%, p=0.04)$, while an EDS cut-off score of 15 was significantly associated with substance use $(8.2 \%$ v. $1.4 \%$, $p=0.004)$ as well as alcohol dependence ( $23.1 \%$ v. $3.1 \%)$.

Conclusions. We found high rates of both alcohol abuse and antenatal depression, and a significant association between depression, substance use and alcohol abuse; EDS scores greater than 12 could be used to identify women at risk of alcohol dependence and/or substance abuse.

S Afr Med J 2012;102(11):851-854. DOI:10.7196/SAMJ.5019
Department of Psychiatry, University of Cape Town, and MRC Research Unit on Anxiety and Stress Disorders, Department of Psychiatry, Stellenbosch University B Vythilingum, MB ChB, FCPsych

D J Stein, $\mathrm{MD}, \mathrm{PhD}$

MRC Research Unit on Anxiety and Stress Disorders, Department of Psychiatry, Stellenbosch University

A Roos, $\mathrm{PhD}$

S C Faure, MA (Counselling Psych)

Department of Obstetrics and Gynaecology, Stellenbosch University L Geerts, MRCOG

Corresponding author: B Vythilingum (bavanisha.vythilingum@uct.ac.za)
South Africa has the highest rates of fetal alcohol spectrum disorders (FASD) in the world, with rates of over 70/1 000 in the Western Cape, one of the worst affected areas globally. ${ }^{1}$ In contrast, rates of $0.33-2.2 / 1$ 000 have been reported for the US population. ${ }^{1}$ Despite numerous intervention efforts, the prevalence of FASD is increasing. ${ }^{1}$ Depression and anxiety in pregnancy consistently predict women who continued to use alcohol and substances in pregnancy ${ }^{2}$ and those who were highrisk drinkers antenatally. ${ }^{3}$ Depression may serve as both an initiating and a maintaining factor for alcohol and substance use in pregnancy.

To our knowledge, there are no published South African data on both alcohol and substance use in pregnancy, or the effects of antenatal depression (AND) on alcohol and substance use. Women in low- and middle-income countries have rates of postnatal depression (PND) comparable to and often higher than their counterparts in the developed world. ${ }^{4,5}$ Meta-analyses have shown that depression 
during pregnancy is an important risk factor for $\mathrm{PND},{ }^{6}$ yet few data are available on AND.

In South Africa there has been, to our knowledge, only one published study of antenatal depression, ${ }^{7}$ which found a $40 \%$ rate of AND in a study of rural women from KwaZulu-Natal. This is of particular concern, as not only is AND a potent risk factor for PND, but it is associated with significant distress. AND has been associated with poor obstetric outcomes including preterm labour, intra-uterine growth restriction and low birth weight. ${ }^{8}$ High rates of AND therefore constitute a significant public health problem, and more data on its prevalence are important in planning appropriate interventions.

A relationship has been shown between higher perceived stress and increased risk of AND and PND. ${ }^{9}$ Higher perceived stress is also associated with an increased risk of relapse after smoking cessation interventions in pregnancy. ${ }^{10}$ There are no studies examining the relationship between perceived stress and alcohol or substance use in pregnancy. However, in non-pregnant women with alcohol and/or substance use disorders, perceived stress is associated with increased use and increased risk of relapse. ${ }^{11}$ South African pregnant women have high levels of perceived stress, ${ }^{12}$ and this may modulate their risk of depression and substance use.

We therefore examined the prevalence and correlates of substance use, depression and perceived stress in a South African antenatal population.

\section{Methods}

All women over the age of 18 presenting for their first antenatal visit at a midwife obstetric unit (MOU) in the East Metropole district, Cape Town, during March 2008 were asked to participate. Subjects who consented completed a self-report questionnaire comprising a demographic and lifestyle questionnaire, the Alcohol Use Disorders Identification Test (AUDIT), the Drug Use Disorders Identification Test (DUDIT), the Edinburgh Depression Scale (EDS), and the Perceived Stress Scale (PSS). It was administered by a research assistant in a private room adjacent to the main clinic. To accommodate participants with limited literacy, the research assistant read out questions. All women gave informed consent for participation. Ethical approval was obtained from the ethics committee of Stellenbosch University.

The demographic and lifestyle questionnaire was designed for the study and collected demographic data (age, marital status, income and level of education), data on past pregnancies and current and past smoking.

The Edinburgh Depression Scale (EDS) ${ }^{13}$ is a 10 -item self-report scale, validated antenatally and postnatally, ${ }^{14}$ that is the most accepted measure of depression in pregnancy and the puerperium. The validated ${ }^{15}$ cut-off score for South African populations is 12 . However, it has been proposed that a higher cut-off score of 15 is more appropriate for women in pregnancy. ${ }^{16}$ We used both cut-off scores.

The Perceived Stress Scale (PSS $)^{17}$ is a 4 -item self-report scale used to assess perceived stress, including factors of being overwhelmed and feeling out of control.

The Alcohol Use Disorders Identification Test (AUDIT) ${ }^{18}$ is a 10 -item screening instrument designed to identify drinkers at risk for alcohol abuse and dependence. Scores above 6 indicate risky drinking and above 20 indicates alcohol dependence.

The Drug Use Disorders Identification Test (DUDIT) ${ }^{19}$ is an 11-item self-report questionnaire, which looks at frequency of drug use. A cut-off score of 2 indicates drug-related problems and 25 or more probable drug dependence.
Descriptive analyses were performed as appropriate. Subjects scoring above the EDS cut-off scores were compared with those scoring below these cut-points. The chi-square test and separate one-way analyses of variance (ANOVA) were used to examine differences in demographic factors and in smoking, alcohol use, drug use and perceived stress. Logistic regression analyses were performed to determine whether EDS scores and demographic factors could distinguish patients using alcohol and drugs from those who did not use them. Alpha for the item entry was set at 0.01 and alpha for the item removal entry at 0.05 . Finally, a receiver operating characteristic curve (ROC) analysis was performed. The area under the ROC curve (AUC) indicates a particular scale's diagnostic ability to discriminate between individuals with and without a particular diagnosis ${ }^{20}$.

\section{Results}

The questionnaire was completed by 323 women (98\% of eligible subjects). Their mean age was 24.6 years (SD 5.5); $88.3 \%$ were coloured, 9.8\% black, $1.5 \%$ white and $0.3 \%$ Indian; and 139 (43.9\%) were primiparous. The mean gestational age was 15.5 weeks (standard deviation (SD) 6.9), with $42.4 \%$ in the first trimester of pregnancy, $48.9 \%$ in the second trimester and $8.7 \%$ in the third trimester. Most women $(37.7 \%)$ described themselves as single, $25.2 \%$ were married, $20.2 \%$ lived with their partner but were not married, a further $16.0 \%$ had a partner but did not live with them, and $0.3 \%$ was divorced; $46 \%$ were employed.

Smoking, alcohol and substance use. Of the women, 116 (36.8\%) smoked, 66 (20.2\%) used alcohol and $13(4 \%)$ used substances at the time of their first antenatal visit; 126 (40.4\%) smoked, 115 (35.3\%) used alcohol and 18 (5.5\%) used substances in the periconceptual period (in the 3 months before they found out that they were pregnant). Periconceptual alcohol use was significantly associated with alcohol use in pregnancy $(54.8 \%$ v. $1.4 \%, p<0.001)$, and periconceptual substance use was similarly significantly associated with substance use in pregnancy ( $50 \%$ v. $1.3 \%, p<0.0001)$. Of the 66 women using alcohol in pregnancy, 58 completed the AUDIT; their mean AUDIT score during pregnancy was 10.4 (SD 7.1). Of the 58 women who completed the AUDIT, 7 scored above 20 . As only 6 women completed the full DUDIT questionnaire the DUDIT data were not analysed.

Depression and stress. The mean score for the EDS was 12.6 (SD 6.3) and that for the PSS 8.1 (SD 3.3). Using EDS cut-off scores of 12 and 15 , respectively, $48.9 \%$ and $33.6 \%$ of the sample had antenatal depression. There was a significant positive correlation between the EDS and PSS total scores $(r=0.195, p<0.001)$. There were no significant differences in age, marital status, employment, parity and gestational age at booking between women with depression and women without depression (as determined using both cut-off scores).

Associations between depression, stress and smoking, alcohol and other substances. There was a significant positive correlation between the total EDS score and drug use $(0.111, p=0.047)$ and with alcohol use $(0.180, p=0.001)$. The EDS total score was also significantly positively correlated with the total AUDIT score $(0.29, p=0.022)$.

An EDS cut-off score of 12 was significantly associated with both alcohol use $(25.9 \%$ of women with a score above 12 used alcohol v. $15.2 \%$ of women scoring below $12 ; p=0.019)$ and risky drinking (76.9\% scoring above 12 had scores indicative of risky drinking v. $36.8 \%$ of women with a score below 12; $p=0.04$ ). In contrast, an EDS cut-off score of 15 was significantly associated with substance use ( $8.2 \%$ of women scoring above 15 used substances v. $1.4 \%$ of women who scored below $15 ; p=0.004)$ as well as alcohol dependence $(23.1 \%$ 
of women who scored above 15 had alcohol dependence v. $3.1 \%$ of women who scored below $15, p=0.038$ ).

Owing to sample size limitations, logistic regression analysis was only performed for alcohol use in pregnancy. Periconceptual alcohol use here emerged as the only predictor of continued alcohol use during pregnancy (odds ratio (OR) 4.522, $p=0.000$ ).

The ROC analysis for alcohol use in pregnancy showed an AUC of 0.583 for an EDS cut-off score of 12, 0.553 for an EDS cut-off score of 15 , and 0.876 for periconceptual alcohol use (Fig. 1). The ROC analysis for substance use in pregnancy showed an AUC of 0.636 for an EDS cut-off score of 12, 0.712 for an EDS cut-off score of 15, and 0.819 for periconceptual substance use (Fig. 2). Table 1 presents sensitivity and specificity scores.

No associations between smoking and depression (using either EDS cut-off score) were found. Similarly, no associations between the PSS and smoking, alcohol and substance use were found.

\section{Discussion}

Our main findings were: (i) high rates of both alcohol abuse and antenatal depression; (ii) a significant association between depression, substance use and alcohol abuse; (iii) that many women using alcohol and/or substances stop use once they discover they are pregnant; and (iv) that EDS scores above 12 can be used to identify women at risk of alcohol dependence and/or substance use.

This study confirms previous findings of high rates of antenatal depression in a sample of South African women. ${ }^{7}$ However, the extremely high prevalence using an EDS cut-off score of 12 (almost $50 \%$ ) raises the concern that this cut-off point may not be valid in the South African population. A score of 15 may be a better identifier of depression, and the EDS cut-off scores for pregnant South African women should be revalidated. However, even when using a higher cut-off score, the $30 \%$ rate of depression found is a cause for concern. Furthermore, the EDS and PSS were highly correlated, suggesting that even if the EDS over-identifies depression, pregnant women in this sample are significantly distressed.

The high rates of alcohol use found during pregnancy and in the periconceptual period are consistent with studies of FAS prevalence ${ }^{1}$ and alcohol and substance use in women of reproductive age. ${ }^{21}$ It is important to note that almost half the women who use alcohol spontaneously stop use once they discover they are pregnant. Furthermore, most of those who continue to drink despite falling pregnant exhibit risky drinking behaviour. This is of particular concern as it indicates that these infants are at high risk of developing FASD and their mothers are likely to have increased difficulty in providing appropriate parenting.

The high rates of smoking and substance use in these subjects are further indicators of a population at high risk of poor obstetric outcomes and child developmental problems.

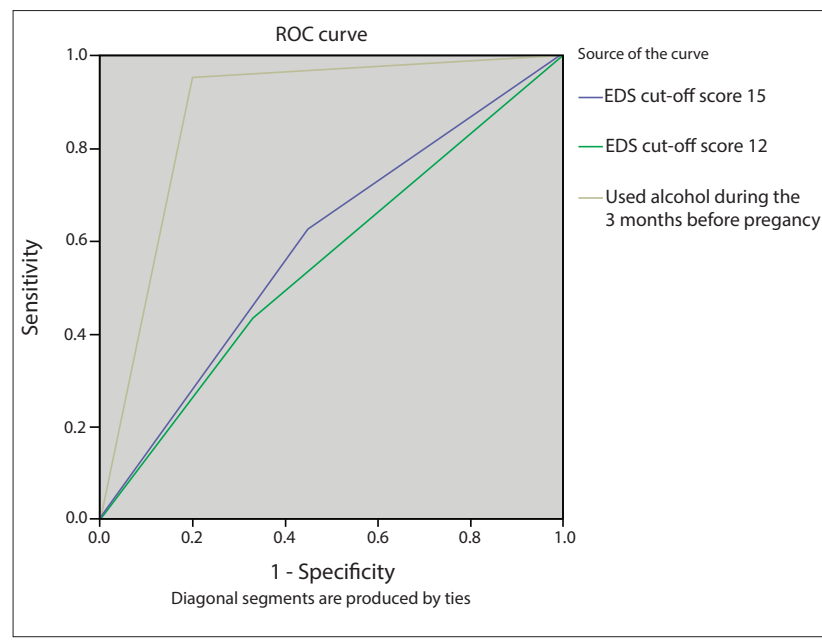

Fig. 1. Predictors of alcohol use in pregnancy.

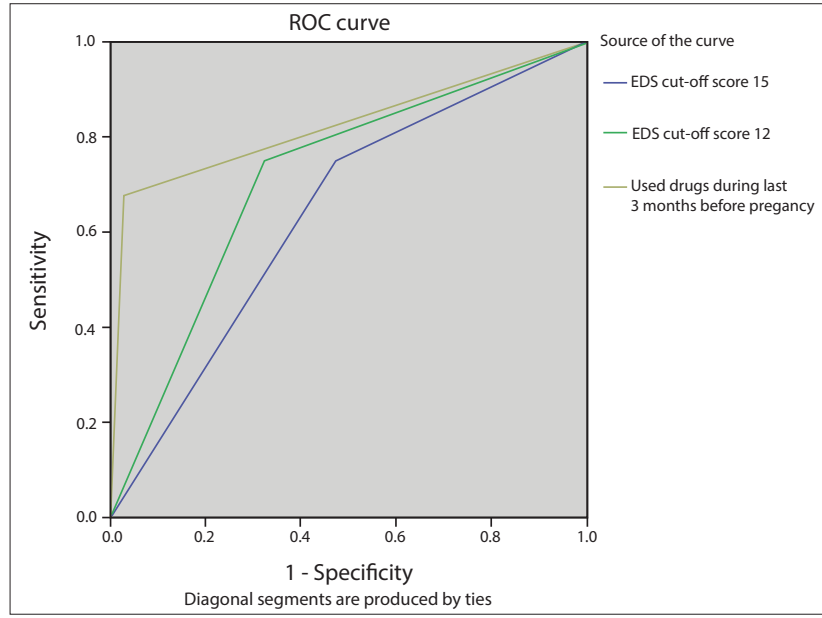

Fig. 2. Predictors of substance use in pregnancy.

The high co-morbidity between depression and alcohol and substance use is in keeping with studies of non-pregnant women. ${ }^{22}$ This is important for several reasons. Firstly, it shows that these women experience a significant burden of disease. In women who are not pregnant, combined interventions addressing both depression and alcohol/substance are most effective. This study suggests that this may also be true for pregnant women. Finally, under-reporting of alcohol and substance use in pregnancy is common. Women may be more likely to admit to depressive symptoms or alcohol/substance use before pregnancy than to current use. Periconceptual use and the presence of antenatal

Table 1. Sensitivity and specificity scores (\%)

\begin{tabular}{|c|c|c|c|c|}
\hline & \multicolumn{2}{|c|}{ Alcohol use in pregnancy } & \multicolumn{2}{|c|}{ Substance use in pregnancy } \\
\hline & Sensitivity & Specificity & Sensitivity & Specificity \\
\hline EDS cut-off score 12 & 62.1 & 54.5 & 75.0 & 52.3 \\
\hline EDS cut-off score 15 & 42.4 & 68.1 & 75.0 & 67.4 \\
\hline Periconceptual alcohol use & 95.5 & 79.8 & - & - \\
\hline Periconceptual substance use & - & - & 66.7 & 99.9 \\
\hline
\end{tabular}


depression may be therefore used as a proxy measure to identify women at risk for alcohol/substance use, and serve as a starting point to build a therapeutic alliance in which substance and alcohol issues can be explored further.

Indeed the regression and ROC analyses show that both periconceptual use and an EDS score of more than 12 can be used as a screening tool to identify women at high risk of alcohol and substance dependence. The EDS is a quick self-report screen that is used in busy antenatal clinics with minimal additional burden on the staff. Screening for depression and risk of alcohol and substance use disorders could therefore potentially be accomplished using the EDS and one question around periconceptual use without needing additional staff time or training, factors that are often cited as barriers to screening.

\section{Limitations of the study}

This study was conducted at two MOUs in Cape Town. It is not known whether these results are generalisable to other areas and populations. Furthermore, the Western Cape is known to be an area where alcohol and substance abuse is rife. Whether the EDS could be used to identify women at risk for alcohol and substance use in populations with a lower prevalence of these disorders is not known. The study also relied on self-report data, which were not verified by a diagnostic interview or laboratory tests. There may therefore be under- or over-reporting of depression, alcohol and substance use disorders. Subjects were also examined at one time point only. We therefore cannot predict any changes in behaviour during the course of pregnancy.

\section{Conclusion}

Alcohol, substance use and depression occur frequently in pregnant women and pose a significant public health problem. Periconceptual alcohol and substance use and antenatal depression are key risk factors for alcohol and substance abuse during pregnancy. Screening for depression and periconceptual use is therefore important to identify and treat women with antenatal depression and to identify women at risk for alcohol and substance use in pregnancy. The high co-morbidity between these conditions also suggests that combined interventions addressing both alcohol and substance use and depression may be needed to adequately treat these women.
Acknowledgements. The authors thank Katherine Sorsdahl and Henri Carrera for their help with statistical analysis.

\section{References}

1. May PA, Gossage JP, Marais AS, et al. The epidemiology of fetal alcohol syndrome and partial FAS in a South African community. Drug Alcohol Depend 2007;88(2-3):259-271. [http://dx.doi.org/10.1016/j. drugalcdep.2006.11.007]

2. Meschke LL, Hellerstedt W, Holl JA, Messelt S. Correlates of prenatal alcohol use. Matern Child Health J 2008;12(4):442-451. [http://dx.doi.org/10.1007/s10995-007-0261-9]

3. Homish GG, Cornelius JR, Richardson GA, Day NL. Antenatal risk factors associated with postpartum comorbid alcohol use and depressive symptomatology. Alcohol Clin Exp Res 2004;28(8):1242-1248. [http://dx.doi.org/10.1097/01.ALC.0000134217.43967.97]

4. Tomlinson M, Cooper PJ, Stein A, Swartz L, Molteno C. Post-partum depression and infant growth in a South African peri-urban settlement. Child Care Health Dev 2006;32(1):81-86. [http://dx.doi. org/10.1111/j.1365-2214.2006.00598.x

5. Husain N, Bevc I, Husain M, Chaudhry IB, Atif N, Rahman A. Prevalence and social correlates of postnatal depression in a low income country. Arch Womens Ment Health 2006;9(4):197-202. [http:// dx.doi.org/10.1007/s00737-006-0129-9]

6. Beck CT. A meta-analysis of predictors of postpartum depression. Nurs Res 1996;45(5):297-303. [http://dx.doi.org/10.1097/00006199-199609000-00008]

7. Rochat TJ, Richter LM, Doll HA, Buthelezi NP, Tomkins A, Stein A. Depression among pregnant rural South African women undergoing HIV testing. JAMA 2006;295(12):1376-1378. [http://dx.doi. org/10.1001/jama.295.12.1376]

8. Koubovec D, Geerts L, Odendaal HJ, Stein DJ, Vythilingum B. Effects of psychologic stress on fetal development and pregnancy outcome. Curr Psychiatry Rep 2005;7(4):274-280. [http://dx.doi. org/10.1007/s11920-005-0081-9]

9. Karacam Z, Ancel G. Depression, anxiety and influencing factors in pregnancy: a study in a Turkish population. Midwifery 2009;25(4):344-356. [http://dx.doi.org/10.1016/j. midw.2007.03.006]

10. Park ER, Chang Y, Quinn V, et al. The association of depressive, anxiety, and stress symptoms and postpartum relapse to smoking: A longitudinal study. Nicotine Tob Res 2009;11(6):707-714. [http:// dx.doi.org/10.1093/ntr/ntp053]

11. Fouquereau E, Fernandez A, Mullet E, Sorum PC. Stress and the urge to drink. Addict Behav 2003;28(4):669-685. [http://dx.doi.org/10.1016/\$0306-4603(01)00276-3]

12. Vythilingum B, Geerts L, Fincham D, et al. Association between antenatal distress and uterine artery pulsatility index. Arch Womens Ment Health 2010;13(4):359-364. [http://dx.doi.org/10.1007/s00737 010-0144-8]

13. Cox JL, Holden JM, Sagovsky R. Detection of postnatal depression. Development of the 10-item Edinburgh Postnatal Depression Scale. Br J Psychiatry 1987;150:782-786. [http://dx.doi.org/10.1192/bjp.150.6.782]

14. Peindl KS, Wisner KL, Hanusa BH. Identifying depression in the first postpartum year: guidelines for office-based screening and referral. J Affect Disord 2004;80(1):37-44. [http://dx.doi.org/10.1016/ for office-based screening
S0165-0327(03)00052-1]

15. Lawrie TA, Hofmeyr GJ, de Jager M, Berk M. Validation of the Edinburgh Postnatal Depression Scale on a cohort of South African women. S Afr Med J 1998;88(10):1340-1344.

16. Matthey S, Henshaw C, Elliott S, Barnett B. Variability in use of cut-off scores and formats on the Edinburgh Postnatal Depression Scale: implications for clinical and research practice. Arch Womens Edinburgh Postnatal Depression Scale: implications for clinical and research pr

17. Cohen S, Kamarck T, Mermelstein R. A global measure of perceived stress. J Health Soc Behav 1983;24(4):385-396

18. Berman AH, Bergman $\mathrm{H}$, Palmstierna T, Schlyter F. Evaluation of the Drug Use Disorders Identification Test (DUDIT) in criminal justice and detoxification settings and in a Swedish population sample. Eur Addict Res 2005;11(1):22-31. [http://dx.doi.org/10.1159/000081413]

19. Bohn MI, Babor TF, Kranzler HR. The Alcohol Use Disorders Identification Test (AUDIT): validation . Bohn MJ, Babor TF, Kranzler HR. The Alcohol Use Disorders Identification Test (AUDIT): validation
of a screening instrument for use in medical settings. J Stud Alcohol 1995;56(4):423-432. [http://
dx doi.org/10.1016/j jast 2003.09.005]

20. Hanley JA, McNeil BJ. The meaning of the use of the area under a receiver operating characteristic (ROC) curve. Radiology 1982;143(1):29-36.

21. Ojo OA, Louwagie G, Morojele N, et al. Factors associated with female high-risk drinking in a rural Ojo OA, Louwagie G, Morojele N, et al. Factors associated with fee
and an urban South African site. S Afr Med J 2010;100(3):180-182.

22. Schuckit MA, Daeppen JB, Tipp JE, Hesselbrock M, Bucholz KK. The clinical course of alcohol-related problems in alcohol dependent and nonalcohol dependent drinking women and men. J Stud Alcohol
probs problems in alcohol 